\title{
Abandoning Patchwork Approaches to Nature of Science in Science Education
}

\author{
Zoubeida R. Dagher, University of Delaware, USA \\ Sibel Erduran, University of Oxford, United Kingdom \& \\ National Taiwan Normal University, Taiwan
}

\begin{abstract}
The purpose of this commentary on Hodson and Wong's paper is to clarify the merits of the Expanded Family Resemblance Approach to science education, briefly alluded to in their paper, and to discuss the implications of this approach relative to the question of demarcation they raise in their paper. In clarifying the merits of the expanded FRA, we describe its distinct features and how it relates to other approaches presented in their paper. We discuss some limitations pertaining to their discussion of the demarcation problem in science education, and conclude by pointing out the promising role an FRA approach might play in providing means for distinguishing more from less scientific fields of inquiry.
\end{abstract}

\section{Introduction}

Hodson and Wong open up the conversation on enriching the scope of NOS curricula. The authors make the case against the consensus view mainly in terms of its overall thrust, its failure to account for scientific practice due to its overly simplified tents, and the overly simplified and naïve nature of its individual tenets. The authors offer alternative approaches to NOS. These include aligning students' practical epistemologies with their formal epistemologies (Sandoval, 2005), Features of Science (Matthews, 2012), Family Resemblance Approach (Erduran \& Dagher, 2014a; Irzik \& Nola, 2011, 2014), Whole Science (Allchin, 2011), and understanding scientific practice (Hodson, 2009). In the concluding section, the authors shift the discussion to demarcation issues and specifically focus on the potential value of using cases of pseudoscience in the classroom to help students distinguish science from pseudoscience.

Although Hodson and Wong raise a number of points that are worthy of commentary, we focus the discussion on two main strands: (a) Clarify our perspective on the merits of the family resemblance approach, briefly described in their paper, and (b) Discuss the implications section of the Hodson \& Wong paper which, instead of building on the earlier discussion, seems to stray away from it.

We view the FRA not as one of many ways to teach and learn about NOS, but as a sophisticated and comprehensive approach for framing NOS related conversations for science education. As for the pedagogical implications of the discussion to curriculum and instruction, we believe that the authors have failed to justify adequately their primary focus on demarcation in science education. Moreover, the authors did not account for, or utilize, the implications of the preceding descriptions of non-consensus view approaches to NOS to support instruction about these cases. Even though Hodson and Wong's paper is entitled "enriching the scope of NOS-oriented curricula" their paper seems to be more focused on curriculum issues than general NOS concerns. In this commentary, we take a broad approach that is inclusive of, but not limited to, the science curriculum. 


\section{The Merits of the Family Resemblance Approach}

The family resemblance approach (FRA) is briefly described in Hodson and Wong's paper in terms of its cognitive, epistemic, and social institutional dimensions. The bare description of the FRA categories, however, obscures its tremendous pedagogical and practical utility for guiding curriculum development and instruction. The main thrust of our and Irzik and Nola's (2014) Family Resemblance Approach is to communicate and assert the importance of addressing critical cognitive, epistemic and social-institutional aspects of science in school science. Science constitutes a system that involves aims and values, practices, methods and methodological rules, knowledge, social ethos, social values, professional activities, social certification and dissemination, social organizations and interactions, financial systems, and political power structures. These categories express classes of ideas about science that are not meant to be exclusive and distinct. Rather they relate to one other in a dynamic and interactive fashion. The interplay between these categories can be visualized in the FRA Wheel (see Figure 1). We believe that understanding the nature of science in science education requires an appreciation of a collective and holistic account of science that is captured by these categories.

While Hodson \& Wong acknowledge that "Erduran and Dagher (2014[a]) have provided a detailed discussion of the implications of Irzik and Nola's theorizing for curriculum content, pedagogy, and learning outcomes", they do not outline or explore these implications. Hence we use this opportunity to do just that. Understanding how the components of this approach function is key for appreciating its viability as a meaningful heuristic for guiding curriculum and instruction. An elaborate account of the Expanded FRA is fully described and summarized elsewhere (Erduran \& Dagher, 2014a; Dagher \& Erduran, 2016). Instead of rehashing the details we highlight the merits of the FRA to NOS and relate it to the other approaches surveyed by Hodson and Wong. 


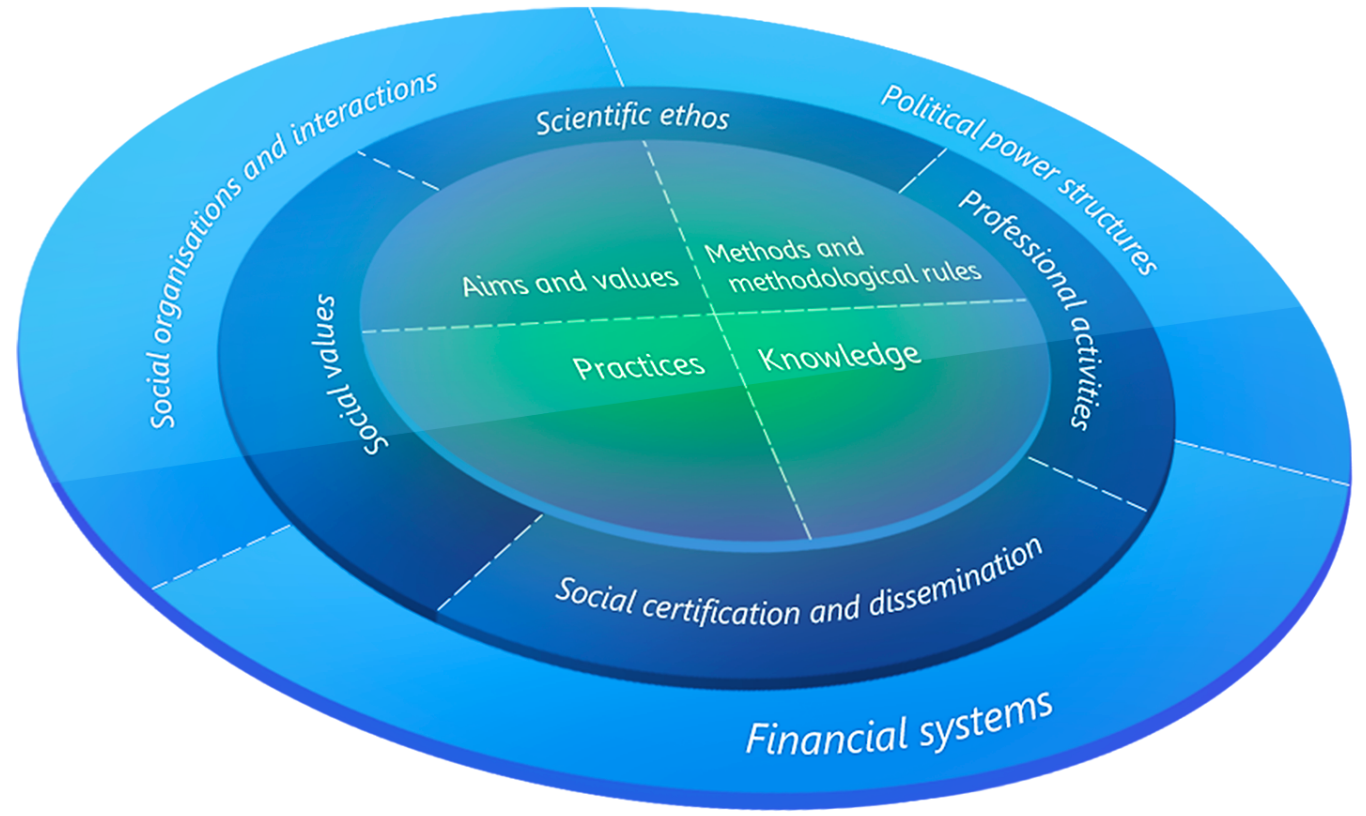

Figure 1. The FRA Wheel (Reprinted from Erduran \& Dagher, 2014a, p. 28).

Taken collectively the categories create focused spaces for contextualized exploration of thematic NOS components throughout instructional sequences. From a curriculum perspective, this should not be translated to merely adding text boxes next to exposition of science concepts in textbooks, but implies the necessity of reconceptualizing concepts by integrating aims and values of science into scientific practices, exploring methods when engaging with practices, alluding to financial systems when these influence the direction of the research and involving students with metacognitive reflection on classroom inquiries. To support the integration of the different NOS categories we proposed a set of visual tools, "Generative Images of Science" (GIS), that support teachers in guiding student reflection on scientific methods and ethical norms when engaging with scientific practices, discussing the values that guide the choice of research questions, research methods, explanatory structures, and exploring organizational structures and societal values that influence or undergird scientific activities.

The overview of the FRA approach provided by Hodson and Wong's paper does not allow for a full appreciation of its implications for science education. In addition, the authors survey multiple approaches to NOS in school science but do not attempt to synthesize or relate them to one another. Indeed, the presentation of the various approaches to NOS is rather 'patchy' in the sense of briefly describing them without relating them to one another or presenting arguments for how/why some of these approaches might be more promising than others. This results in a "patchwork of approaches" that underscore the lack of a conceptual rationale or a coherent overall vision for NOS. While Hodson and Wong criticise the consensus view, their proposal to 
overcome some of the limitations of the consensus view by using the alternative approaches could have been better supported.

This is akin to a dietician providing clients with several healthy meal plan options and advising them to select food items from one of the plans, or select items from any of them. Two potential problems arise: Is the client to assume that these meal plans are equally healthy? And, would selecting any one item from one meal plan with an item from the other plan ensure a healthy meal? The answer to both questions is: "not necessarily". Some of the meal plans may have more nutritious food groups than others and contain more healthy nutrients within their individual offerings. Mixing any items from two different meal plans may result in picking two desserts and leaving out the main course. Random selections are not how informed individuals typically decide on their meals. By the same token, they not how educators and curriculum developers make their decisions. Those are typically based on critical analysis of best practices relative to carefully identified goals.

A Family Resemblance Approach for NOS provides an overall coherent theoretical justification and advances the rich facets of science as cognitive, epistemic and social-institutional system. Indeed, in our book (Erduran \& Dagher, 2014a), we have drawn on a vast amount of literature to justify the overall theoretical framework of FRA as well as its adaptation for science education. We have done so by appealing to science studies literature to illustrate and justify each FRA category, and referred to science education policy and research documents to demonstrate the relevance of FRA for educational applications. Such a systematic approach ensures that there is coherence among ideas. Just as in a life science course disparate concepts such as organelles and related physiological processes (e.g. 'mitochondria', 'chloroplast', 'respiration', 'photosynthesis') get meaning and coherence under the theory of the cell, an overall theoretical framework like FRA provides an organizational scheme for relating different characteristics of NOS in a coherent manner. It allows the appreciation of how different aspects of science work together as a system.

How does the FRA relate to existing NOS frameworks? In Figure 2 below, we represent the relationship between Family Resemblance Approaches to NOS (Erduran \& Dagher, 2014a; Irzik \& Nola, 2014) and others surveyed by Hodson and Wong using a series of concentric circles whereby each circle attends to the listed components and those of all the circles it encloses. Almost all of the alternative approaches emphasize scientific methods and practices. Allchin's and Hodson \& Wong's views, address aspects of aims and values, methods and socio-cultural aspects with Allchin placing different emphases on historical approaches and current socioscientific issues. Family resemblance approaches subsume all aspects proposed by other colleagues, except for those features of science in Matthews' account that address philosophical stances such as realism, feminism and other -isms. Sandoval's (2005) four epistemological themes focus on the scientific knowledge and practices although the author does not explicitly refer to "nature of science" in characterizing these concepts. 


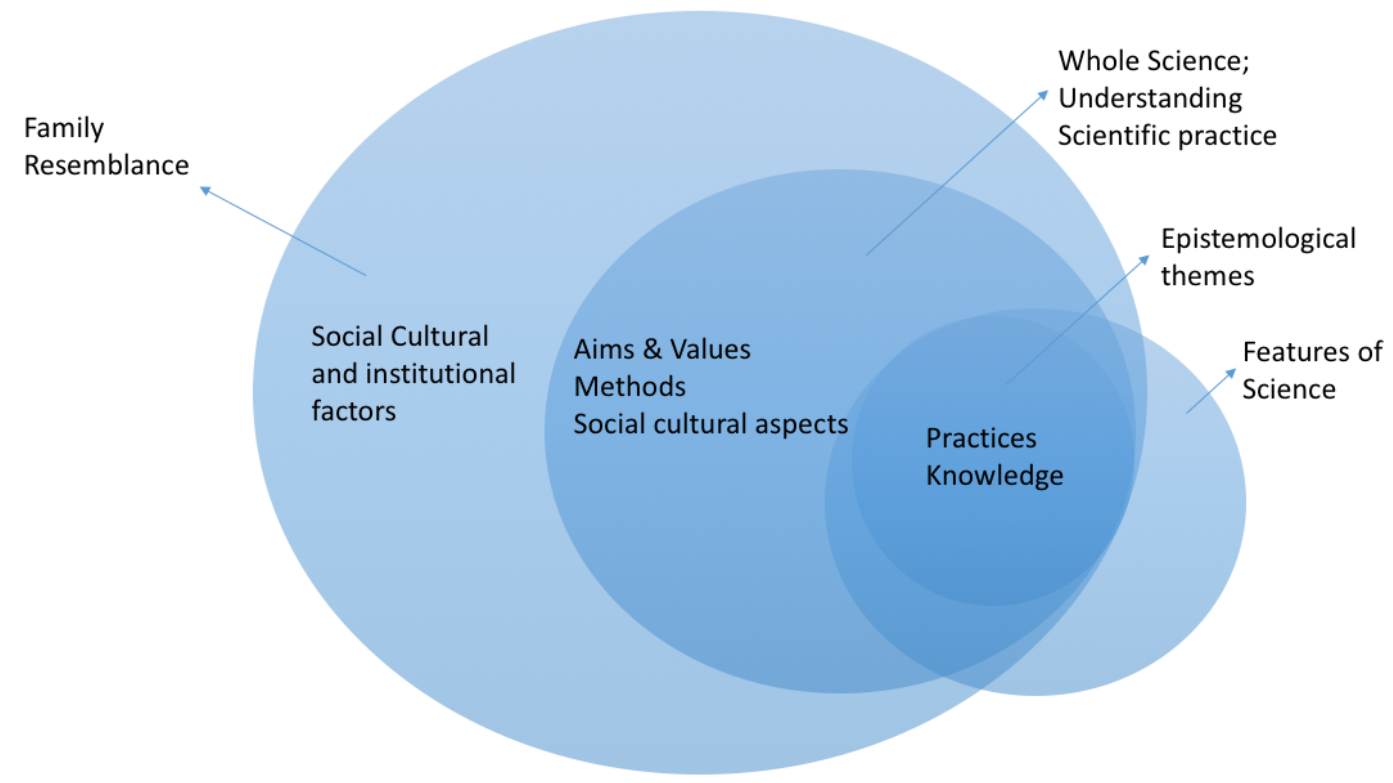

A curriculum that endorses science as a cognitive-epistemic system focusing mainly on few aspects of science will differ dramatically from one that endorses science as cognitive-epistemic and a social-institutional system. This is not about shifting semantics but involves recognizing the significance of identified categories to those enterprises we deem scientific. The distinctions and conclusions drawn here matter for defining NOS knowledge of most worth. In our view, the family resemblance that characterizes scientific domains also serves the double duty of exposing their shared and, by contrast, their unique attributes.

The expanded FRA provides a comprehensive non-trivial approach to implementing rich understandings of nature of science in K-16 curricula. It also provides a fruitful research program by virtue of the new questions and methodologies it has opened up for research in science education. For example, the analytical tools pertaining to the expanded FRA (Erduran \& Dagher, 2014a) have enabled a more systematic analysis of curriculum frameworks (Dagher, 2012; Erduran and Dagher, 2014b, Kaya and Erduran, 2016), and textbooks (BouJaoude, Dagher, \& Refai, 2017; McDonald, 2017). It has also informed discussions with science faculty in higher education (Dagher, 2015), and has been taught in graduate level courses in Taiwan and Turkey. One of the tools within the Expanded FRA that is focused on scientific practices, namely the Benzene Ring Heuristic (BRH) has been used with preservice science teacher educators (Erduran, Kaya \& Dagher, in press; Erduran, Dagher, Mugaloglu, Kaya, Saribas, \& Ceyhan, 2015) and in professional development workshops for teachers in Lebanon and Turkey, supported by resources specifically written for teacher educators (Erduran, Mugaloglu, Kaya, Saribas, Ceyhan, \& Dagher, 2016). A potential criticism of a systemic approach to FRA to NOS in teaching and learning could be that it is too complicated for science teachers. Given the studies just cited we have not confirmed any evidence that shows that this is the case. The FRA provides an ambitious and practical vision for what NOS enriched science content should aim for, and uses evidence-based practices in science education to support the enactment of this vision. 


\section{Implications of Hodson and Wong's Paper}

In the pedagogical implication section, Hodson and Wong state that "a curriculum this extensive in scope demands the deployment of a wide range of learning activities and resources" (p. 20) and proceed to list a plethora of resources. We agree that such resources are very important as long as they are organized with a clear NOS vision. The authors also argue for a careful consideration of the views and perspectives of scientists at the forefront of scientific research and development to support, elaborate and sometimes challenge the NOS views of philosophers of science, sociologists of science and historians of science." (p. 20). We agree that learning experiences can be enriched by learning about scientists (from science studies accounts), learning from scientists, and learning with scientists. We also value the experiential learning that takes place when students participate in investigative projects with practicing scientists. However, we believe that the views scientists at the forefront of science are more likely to supplement rather than challenge the views of philosophers, sociologists and historians of science--since these tend to reflect the diversity of views already represented in these fields.

Instead of building on the foundations developed earlier in the paper, the authors switch abruptly to a sole focus on demarcation issues (four out of five pages dedicated to implications). This is surprising given the tenor of the paper that promises to lay out ground work for "enriching the scope of NOS curricula", and sets up the reader for multiple examples that show how this can be accomplished. Focus on demarcation is justified on the basis of empowering students to avoid the lure of pseudoscientific fields--but the exclusion of other goals for NOS learning in this section is not justified. What other purposes, for example, can a rich NOS education serve?

Returning to demarcation issues, it should be noted that philosophers of science have long debated and attempted solutions with implications that have major social ramifications. These debates are ongoing precisely because the demarcation criteria have not been settled in terms of sets of necessary and sufficient conditions. The stakes are too high to give up on the problem. For as Lakatos once said "The problem of demarcation between science and pseudoscience is not a pseudo-problem of armchair philosophers: it has grave ethical and political implications." (Lakatos, 1973). Ethical and political implications in addition to personal and social implications, justify continued philosophical inquiry. Similar considerations, justify emphasis on this theme as part of a wholesome science education through meticulous consideration of philosophical insights and pedagogical goals.

The challenge for science educators is to help students make practical distinctions between scientific and pseudoscientific claims/fields. Most philosophers of science now agree that arguments based on falsification or method do not provide necessary and sufficient conditions for establishing demarcation, even though they have used such arguments occasionally for practical purposes. A case in point is Ruse's court testimony against the State of Arkansas supporting the argument that creation science is not science. He based his testimony on five main lines of arguments that included: laws; explanation and prediction; testability, confirmation, and falsifiability; tentativeness; and integrity (Ruse, 1982).

Hodson and Wong express preference for Smith \& Scharmann's (1999) call to teachers "not to seek a clear distinction between science and non-science; rather, to generate a set of predictors 
that can be used to judge which fields of study are more scientific or less scientific than others". Among the proposed features for a field claiming to be scientific are its: "empirical character, testability/falsifiability, replicability and tentative status. In addition, science puts high value on theories that exhibit wide-ranging explanatory power, fecundity/fruitfulness, open-mindedness, parsimony and logical coherence" (cited in Hodson \& Wong, this volume, pp. 22-23). Smith and Scharmann's (2008) recourse to features that distinguish exemplars from non-exemplars are justified in the writings of Kuhn, Wittgenstein, Bruner and Nersessian. In principle, this direction is compatible with a Family Resemblance Approach to NOS, though further discussion of the specific features that characterize more from less scientific fields can be further negotiated and refined.

Of concern is Hodson \& Wong's proposal that creation science and evolution be used as a case in the classroom to discuss pseudoscience and science, without acknowledging some of the associated risks. The authors ignore the fact that their proposed use of creationism as a case of pseudoscience in the classroom is highly controversial and particularly delicate in the United States. First, there is a clear separation between church and state and a long history of court cases against including creationism, creation science, and more recently intelligent design as valid scientific theories in school science is well documented - and a high volume of scholarly articles detailing the complications associated with debating creation science and evolution in the classroom in terms of confronting students' religious views render Hodson \& Wong's proposal more complicated and worthy of a more substantive treatment than is included in their paper.

Another issue has to do with including acupuncture as a case of pseudoscience. Allchin's acupuncture case study $(1995,1996)$ is originally proposed to offer comparative insights about the cultural contexts of science. Understanding the incommensurability of the Chinese and Western maps of the body, and how knowledge is obtained and validated are important for understanding the arguments behind claims. This case invites more complex consideration of distinctive criteria, and further work is needed to clarify the basis on which the arguments are being made.

The family resemblance approach has the potential to address demarcation issues. The various family resemblance categories can provide a systematic source of categories that can be used to compare science, non-science and pseudoscience. For example, the aims and values of science, non-science and pseudoscience can be contrasted. Likewise the practices underpinning each can be investigated. The broader set of categories (ranging from aims and values to social organisations and interactions) together might provide some insight into how science, nonscience and pseudoscience fields can be differentiated. Other ways to accomplish this outcome have been proposed. Pigliucci (2013), for example, suggests two main criteria around which fields of knowledge can be characterized: empirical knowledge and theoretical understanding. Fields that have high levels of theoretical understanding and empirical knowledge will cluster differently than those who have lower empirical knowledge and theoretical understanding (see Figure 3). Rather than applying strictly defined demarcation criteria, using indicators that vary along a continuum, such as the two proposed by Pigliucci can provide productive ways for capturing distinctions among more or less closely related fields, thus moving away from sharp dichotomies towards closely associated features. 
Complementary to this idea, Hoyningen-Huene (2013) posits that the more systematic the discipline is, the more scientific it is. He proposes using the notion of systematicity as a way of differentiating science from pseudoscience. We believe that the FRA framework (Erduran \& Dagher, 2014a, Irzik \& Nola, 2014) provides focus areas that allow for comparative consideration of the systemicity "index" of different fields of knowledge (scientific and less scientific) in the science classroom. The relevance of a Family Resemblance Approach to the discussion of demarcation lies in its capacity to provide reliable means for distinguishing between scientific and pseudo-scientific domains.

Recent scholarship in the philosophy of science points to the emergence of fruitful possibilities for application in school science. Understanding degrees of systematicity relative to scientific norms and values, methods and other categories within the expanded FRA, can provide principled tools for making judgements about scientifically sounding claims and scientifically sounding fields. The pursuit of ever refined ways to communicate clearly with teachers and students about these issues, obligate us to follow current debates in science, science education and science studies, and formulate exemplary instructional cases that educate and equip science teachers and students with powerful and critical reasoning tools. It is through engagement with fruitful ideas and constructive debate that we move beyond patchwork approaches towards engaged and enriched nature of science for science education.

\section{References}

Allchin, D. (2011). Evaluating knowledge of the nature of (whole) science. Science Education, 95, 518-542.

BouJaoude, S., Dagher, Z., \& Refai, S. (2017). The Portrayal of Nature of Science in Lebanese 9th Grade Science Textbooks. In C. McDonald \& F. Abd-El-Khalick (Eds.), Representations of Nature of Science in School Science Textbooks: A Global Perspective. Routledge.

Dagher, Z. (2012). Re-imagining nature of science: Implications for policy and research. Paper presented at the Annual meeting of NARST: A worldwide organization for improving science teaching and learning through research, Indianapolis, Indiana, March 25-28.

Dagher, Z. (2015). Using images of science to enrich the integrated science curriculum. Invited informal seminar with Preceptors at the Interdisciplinary Science and Engineering Laboratory. University of Delaware, January 12.

Dagher, Z. \& Erduran, S. (2016). Reconceptualizing the nature of science for science education: Why does it matter? Science \& Education, 25(1), 147-164. DOI 10.1007/s11191-015-9800-8.

Erduran, S. \& Dagher, Z. (2014a). Reconceptualizing the nature of science for science education: Scientific knowledge, practices and other family categories. Dordrecht: Springer. 
Erduran, S. \& Dagher, Z. (2014b). Regaining focus in Irish junior cycle science: Potential new directions for curriculum and assessment development on nature of science. Irish Educational Studies, 33(4), 335-350.

Erduran, S., Dagher, Z., Mugaloglu, E., Kaya, E., Saribas, D. \& Ceyhan, G. (2015). Defining and understanding scientific practices in pre-Service science teacher education. Symposium presented at the Annual meeting of NARST: A Worldwide Organization for Improving Science Teaching and Learning through Research. Chicago, IL, April 11-14.

Erduran, S., Mugaloglu, E., Kaya, E., Saribas, D., Ceyhan, G. \& Dagher, Z. (2016). Learning to teach scientific practices: A professional development resource. Limerick: University of Limerick, Ireland. DOI: 10.13140/RG.2.2.31352.44806

Erduran, S., Kaya, E., \& Dagher, Z. (in press). From lists in pieces to coherent wholes: revisiting the nature of science in science education. In, J. Yeo, T. W. Teo \& K. S. Tang (Eds.), Research and Practice in the Asia-Pacific Region. Dordrecht: Springer.

Hodson, D. (2009). Teaching and learning about science: Language, theories, methods, history, traditions and values. Rotterdam: Sense.

Hoyningen-Huene, P. (2013). Systematicity: The nature of science. Oxford: Oxford University.

Irzik, G. \& Nola, R. (2014). New directions for nature of science research. In M. Matthews (Ed.), International handbook of research in history, philosophy and science teaching (pp. 999-1021). Dordrecht: Springer.

Kaya, E., \& Erduran, S. (2016). Yeniden kavramsallaştırılmış "Aile Benzerliği Yaklaşımı": fen eğitiminde bilimin doğasına bütünsel bir bakış açısı, Türk Fen Eğitimi Dergisi, 13(2), 76-89, ISSN:1304-6020, DOI: 10.12973/tused.10180a

Lakatos, I. (1973). Science and pseudoscience. Retrieved from: http://www.lse.ac.uk/philosophy/department-history/science-and-pseudoscience-overview-andtranscript/

McDonald, C. V. (2017). Exploring representations of nature of science in Australian junior secondary school science textbooks: A case study of genetics. In C. V. McDonald \& F. Abd-ElKhalick (Eds.). Representations of Nature of Science in School Science Textbooks: A Global Perspective. New York: Routledge.

National Health Institute (2011). Understanding acupuncture. Retrieved from https://newsinhealth.nih.gov/issue/feb2011/feature1

Pigliucci, M. (2013). The demarcation problem: A (belated) response to Laudan. In, M. Pigliucci \& M. Boudry (Eds), Philosophy of pseudoscience: Reconsidering the demarcation problem (pp. 9-28). Chicago: University of Chicago Press. 
Ruse, M. (1982). Creation science is not science. Science, Technology, and Human Values, 7(40), $72-78$.

Sandoval, W. (2005). Understanding students' practical epistemologies and their influence on learning through inquiry. Science Education, 89(4), 634-656.

Smith, M. \& Scharmann, L. (2008). A multi-year program developing an explicit reflective pedagogy for teaching pre-service teachers the nature of science by ostention. Science Education, 17, 219-248. DOI 10.1007/s11191-006-9009-y 